\title{
PENGENALAN KARAKTER JAWI TULISAN TANGAN MENGGUNAKAN FITUR SUDUT
}

\author{
Safrizal \\ Akademi Komunitas Negeri Aceh Barat \\ Komplek STTU Alue Peunyareng, Aceh Barat, 23615 \\ e-mail: safrizal@aknacehbarat.ac.id
}

\begin{abstract}
Abstrak - Karakter Jawi salah satu varian karakter Arab adalah karakter Jawi. Karakter tersebut mengakomodasi penulisan bahasa Melayu. Karakter Jawi banyak digunakan oleh kerajaan Islam di Nusantara sehingga banyak dokumen menggunakan karakter tersebut. Untuk menjaga kelestarian dokumen tersebut maka karakter Jawi tersebut harus di rubah kedalam format digital, salah satu caranya adalah dengan metode Optical Character Recognition (OCR). Salah satu metode OCR dalam mengekstraksi fitur adalah menggunakan sudut yang dibentuk dari bagian utama karakter. Fitur yang dihasilkan dari sudut tersebut digunakan oleh SVM untuk di klasifikasi kedalam karakter Jawi. Dengan menggunakan fitur tersebut, SVM mampu mengklasifikasi karakter Jawi dengan tingkat akurasi rata-rata sebesar $\mathbf{7 8 , 8 6 \%}$.
\end{abstract}

Kata kunci : OCR, Jawi, sudut, SVM

Abstract-The Jawi character is one variant of Arabic characters that adopts Malay language writing. The character of Jawi is widely used by the Islamic kingdom in the Archipelago. Many document written using these characters. To preserve the history and the book, the Jawi character need to be converted into digital form, one way is by Optical Character Recognition (OCR) method. One method of OCR in extracting features is to use angles formed by main part of the character. The features generated are used by SVM to be classified into Jawi characters. By using these features, SVM is able to classify Jawi characters with an average level of accuracy of $78.86 \%$.

Keywords: OCR, Jawi, angle, SVM

\section{PENDAHULUAN}

Optical Character Recognition (OCR) merupakan bagian dari computer vision dan machine learning yang menerjemahkan karakter hasil cetakan komputer atau tulisan tangan kedalam format digital yang dapat diedit [1]. Pengenalan karakter dapat dilakukan secara online maupun offline. Pada pengenalan karakter secara online, karakter atau teks ditulis secara langsung pada perangkat elektronik, misalnya telepon genggam, tablet dan personal data assistant. Pada pengenalan karakter secara offline, karakter atau teks di tulis pada kertas dan kemudian di pindai menggunakan scanner. Pengenalan karakter secara offline lebih sulit dibandingkan dengan online [2].

Pada awalnya, pengenalan karakter hanya dilakukan pada karakter-karakter yang tidak terhubung, misalnya karakter latin. Seiring perkembangan metode ekstraksi fitur dan klasifikasi, pengenalan karakter mengalami peningkatan performansi serta mampu mengenali karakter-karakter dalam bentuk terhubung, misalnya karakter Arab [3]. Karakter Arab tersebut diadopsi oleh karakter-karakter bahasa lain misalnya Jawi dan Farsi untuk mengakomodasi bahasa lokal. Karakter Jawi terdiri 35 aksara, yang terdiri dari 29 aksara berdasarkan bahasa Arab dan 6 karakter tambahan untuk mengakomodasi bahasa Melayu [3].
Penelitian pengenalan karakter Jawi relatif lebih sedikit dibandingkan dengan penelitian aksara Arab, Jepang, Cina dan Latin [4]. Beberapa penelitian sebelumnya tentang pengenalan aksara Jawi dilakukan oleh [5] menggunakan Hidden Markov Models, [6] menggunakan Trace Transform, [4] menggunakan FCC dan SVM dan [7] menggunakan Hybrid Artificial Neural Networks dan Dinamic Programming.

Karakter Jawi saat ini tidak lagi digunakan pada kegiatan resmi kenegaraan. Padahal banyak sekali sejarah-sejarah kerajaan serta kitab-kitab agama Islam ditulis dalam bahasa Jawi. Untuk menjaga kelestarian sejarah dan ilmu agama Islam diperlukan sebuah metode yang mampu menghasilkan dokumen digital, salah satu metodenya adalah OCR.

\section{STUdI PUSTAKA}

Agar dapat diklasifikasi oleh classifier diperlukan beberapa proses pre-processing agar menghasilkan fitur yang optimal. Proses pre-processing tersebut adalah binerisasi dan thinning.

\section{A. Binerisasi}

Pada saat dipindai, citra dari setiap karakter biasanya memiliki noise. Untuk menghilangkan noise tersebut dilakukan pre-processing. Pada tahap pre-processing, setelah dihilangkan noise maka biasanya dilakukan 
binerisasi. Binerisasi merupakan proses memisahkan nilai pixel dari citra kedalam dua bagian yaitu bagian latar (background) dan bagian tulisan (foreground) [8]. Terdapat dua metode dalam proses binerisasi yaitu binerisasi global dan binerisasi lokal. Beberapa teknik binerisasi global yaitu fixed thresholding method, metode Otsu dan Metode Kittler. Pada binerisasi lokal, teknik yang digunakan biasanya metode Niblack, metode adaptif, metode Sauvola dan metode Bernsen [9].

Salah satu metode binerisasi yang cukup popular dalam pengenalan karakter adalah metode Otsu. Metode Otsu melakukan binerisasi secara otomatis pada suatu dokumen berdasarkan bentuk dari histogram [10]. Metode ini mencari sebuah nilai threshold optimum untuk memisahkan antara background dan foreground. Nilai threshold optimum tersebut adalah $k$, nilai $k$ ini merupakan level threshold dan $L$ merupakan level keabuan citra [10].

$$
\sigma_{B}^{2}(k *)=\max _{1 \leq k \leq L} \sigma_{B}^{2}(k)
$$

\section{B. Thinning}

Citra karakter tulisan tangan biasanya memiliki ketebalan lebih satu pixel. Ketebalan pixel dapat berbeda tergantung dengan jenis alat tulis yang digunakan. Perbedaan tersebut dapat mengakibat fitur tidak optimal. Untuk mengoptimalkan fitur agar dapat diklasifikasi dengan baik, maka dilakukan pengikisan ketebalan menjadi satu pixel. Proses pengikisan disebut dengan thinning yang akan menghasilkan kerangka karakter.

Salah satu metode thinning yang cukup popular adalah metode Zhang Suen [11]. Metode tersebut kemudian di modifikasi agar dapat menghasilkan kerangka yang lebih baik dengan mempertahankan pixel diagonal dan persegi dengan 8 konektivitas tetangga [12].

\begin{tabular}{|c|c|c|}
\hline$z 4$ & $z 3$ & $z 2$ \\
\hline$z 5$ & $p$ & $z 1$ \\
\hline$z 6$ & $z 7$ & $z 8$ \\
\hline
\end{tabular}

Gambar 1. 8 - konektivitas tetangga Zhang Suen hasil modifikasi [12]

\section{Metode}

\section{A. Objek Penelitian}

Penelitian ini menggunakan karakter hasil tulisan offline dari 10 orang penulis dengan latar belakang pendidikan, profesi dan usia yang berbeda. Masing-masing penulis diminta untuk menuliskan karakter Jawi pada kertas HVS dengan latar belakang putih. Karakter Jawi tersebut di scan dan di crop dengan ukuran berkisar antara $148 \times 148$ px sampai dengan $179 \times 177$ px. Karakter hasil crop tersebut disimpan dalam sebuah basis data. Karakter hasil tulisan ini juga digunakan pada penelitian [4].

\section{B. Alur Penelitian}

Alur penelitian dimulai ekstraksi fitur sudut dan di klasifikasi menggunakan SVM. Gambar 2 berikut menggambarkan alur lengkap penelitian.

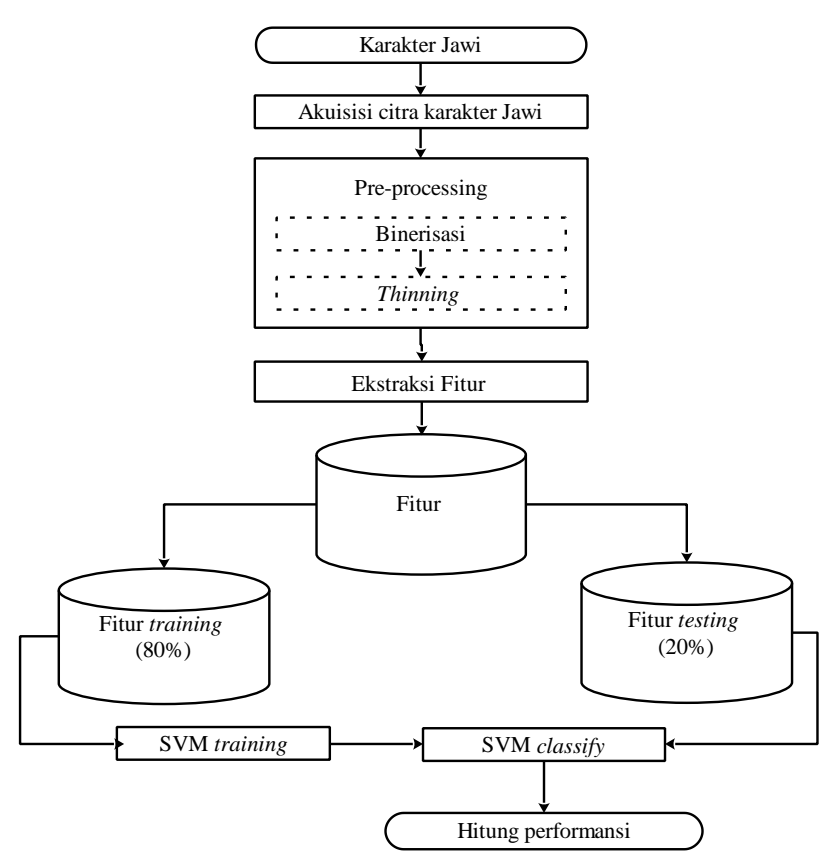

Gambar 2. Alur penelitian

\section{Ekstraksi Fitur Jumlah Titik}

Seperti halnya pada karakter Arab, karakter Jawi juga memiliki titik. Terdapat beberapa karakter Jawi yang memiliki bentuk bagian utama yang sama, misalnya karakter " $b a$ ", " $t a "$ dan "tsa" namun memiliki jumlah dan letak titik yang berbeda.

Pada penelitian ini, titik didefinisikan sebagai luas pixel yang terhubung antara 1 sampai dengan 30 pixel. Jika ditemukan nilai pixel 1 pada karakter biner, maka akan dilakukan penulusuran konektivitas dengan mask 3x3. Jika konektivitas lebih dari 30 pixel maka dianggap sebagai bagian utama karakter. Jika jumlah titik satu maka fitur jumlah titik $(J T)$ adalah satu [JT=1], jika ditemukan dua titik maka $[J T=2]$ dan jika ditemukan tiga titik maka [JT=3].

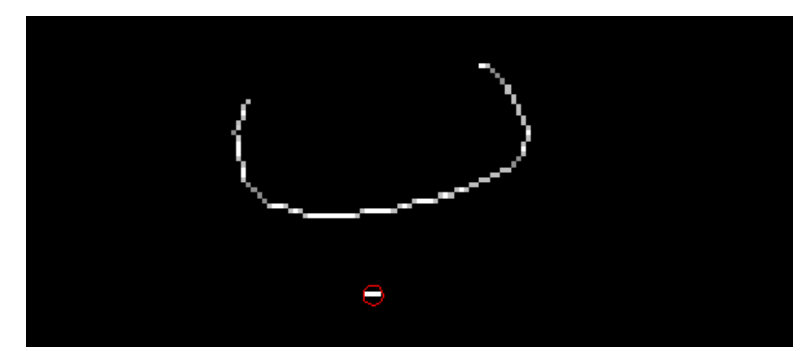

Gambar 3. Ekstraksi fitur jumlah titik

\section{Ekstraksi Fitur Letak Titik}

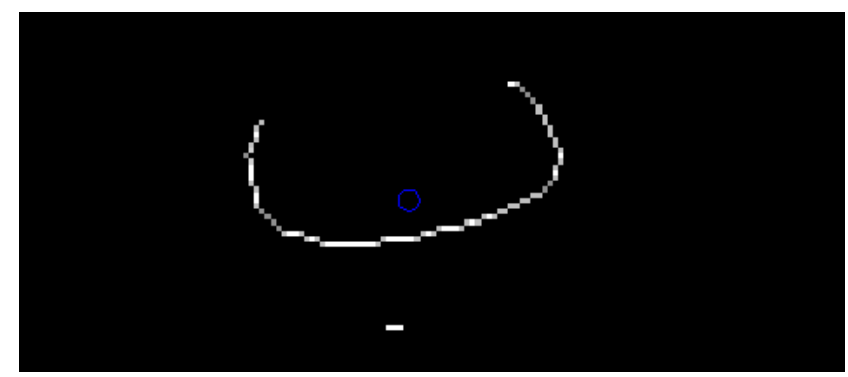

Gambar 4. Pusat massa 
Proses ekstraksi letak titik dimulai dengan menentukan pusat massa dari setiap karakter. Pusat massa merupakan titik sentral dari sebuah karakter termasuk titik. Gambar 4 berikut menunjukkan pusat massa dari karakter " $b a$ ". Perbedaan baris pusat massa dengan baris letak titik dijadikan fitur letak titik ( $L T)$ seperti yang terlihat pada gambar 5. Karena maksimum jumlah titik pada karakter Jawi berjumlah tiga, maka panjang fitur $L T$ adalah 3. Fitur $L T$ disusun dengan format [LT= (Letak Titik 1) (Letak Titik 2) (Letak Titik 3)]

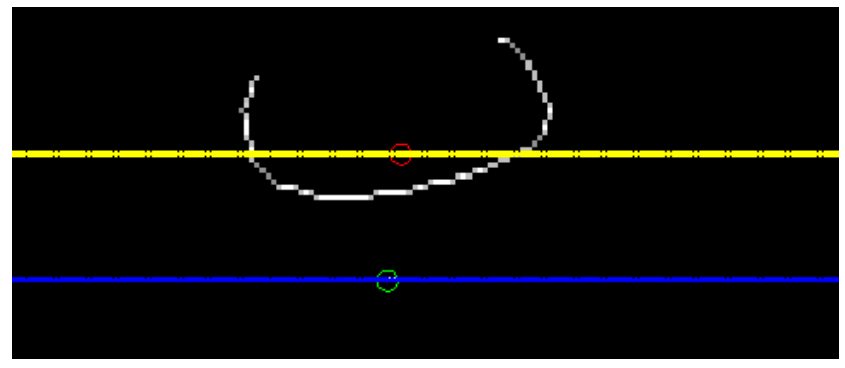

Gambar 5. Selisih baris pusat massa dan letak titik

\section{E. Ekstraksi Fitur Sudut}

Perbedaan kurva menjadi ciri khas bentuk bagian utama karakter Jawi. Perbedaan tersebut membentuk sudut yang berbeda-beda. Dengan mengekstraksi sudut bagian utama aksara maka didapatkan fitur berupa sudut.

Untuk mendapatkan sudut maka bentuk bagian utama karakter dibagi kedalam lima bagian, seperti yang terlihat pada gambar 6. Masing-masing bagian memiliki sudut yang berbeda-beda sehingga menghasilkan fitur yang unik. Fitur sudut $(S)$ disusun kedalam vektor $\left[S=\theta_{1}, \theta_{1}, \theta_{1}, \theta_{1}, \theta_{l}\right]$ Sudut tersebut dihasilkan dari perkalian titik (dot product) dengan menggunakan persamaan 2 berikut.

$$
\theta=\arccos \frac{a \cdot b}{|a| \cdot|b|}
$$

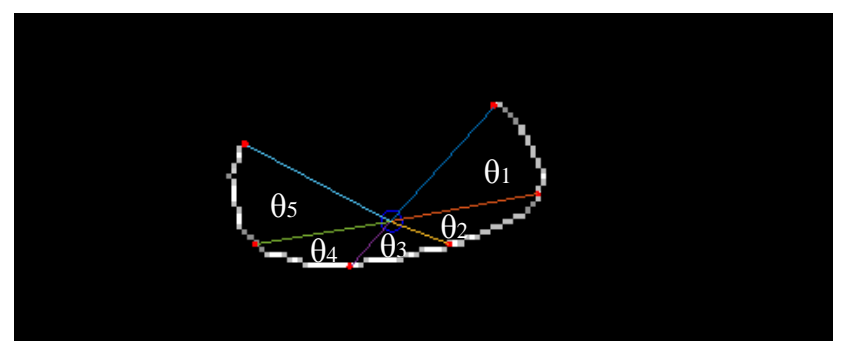

Gambar 6. Pembagian sudut

\section{F. Klasifikasi}

Kemampuan SVM dalam mengklasifikasi multiclass menjadikan klasifikasi seluruh karakter Jawi cukup dilakukan satu kali. Metode yang digunakan untuk klasifikasi multiclass SVM dapat berupa one-against-all dan one-against-one. Penelitian ini menggunakan metode oneagainst-one. Dengan menggunakan metode tersebut maka model klasifikasi biner yang dibangun adalah 35*(351)/2=595 buah. Dari setiap model yang sudah dibangun tersebut diterapkan hasil voting sehingga menghasilkan satu karakter hasil klasifikasi.

\section{G. Prosedur Pengujian}

Seluruh fitur $(F)$ disusun dengan format $[F=J T L T S]$. Fitur tersebut digunakan SVM untuk diklasifikasikan kedalam karakter Jawi. Akurasi klasifikasi dihitung dengan persamaan 3 berikut:

$$
\text { Akurasi }=\frac{\text { Benar } \text { klasifikasi }}{\text { Total klasifikasi }} \times 100 \%
$$

\section{HASIL DAN PEMBAHASAN}

\section{A. Implementasi}

Implementasi pengenalan karakter Jawi menggunakan sudut sebagai fitur membutuhkan beberapa komponen pendukung yaitu aplikasi Matlab dan komputer yang mampu menjalankan aplikasi Matlab tersebut. Implementasi ini secara umum dapat dibagi kedalam beberapa modul, yaitu akuisisi citra karakter, binerisasi, thinning, ekstraksi fitur dan klasifikasi dengan SVM.

\section{B. Hasil Pengujian}

Pada pengujian ini, karakter hasil akusisi melalui scanner yang berjumlah 350, dibagi kedalam dua bagian yaitu karakter training dan karakter testing. $80 \% \times 350=280$ karakter dijadikan sebagai fitur training, sedangkan sisanya $20 \% \times 350=70$ karakter dijadikan fitur testing.

Seperti yang terlihat pada gambar 2, pembagian fitur training dan fitur testing dilakukan secara acak. Untuk meningkatkan keakurasian, maka dilakukan pengulangan klasifikasi sebanyak 10 kali, dengan asumsi setiap karakter memiliki probabilitas terpilih sebanyak 1 kali. Hasil pengujian dapat dilihat pada tabel 1 dibawah ini.

Tabel 1. Akurasi hasil pengujian

\begin{tabular}{cc}
\hline Pengujian & Persentase Akurasi (\%) \\
\hline 1 & 80 \\
2 & 78,57 \\
3 & 84,29 \\
4 & 72,86 \\
5 & 81,42 \\
6 & 74,29 \\
7 & 75,71 \\
8 & 78,57 \\
9 & 82,86 \\
10 & 80 \\
rata-rata & $\mathbf{7 8 , 8 6}$ \\
\hline
\end{tabular}

Akurasi paling tinggi yang didapat adalah sebesar 84,29\% sedangkan yang paling rendah adalah sebesar $72,86 \%$. Ratarata keberhasilan klasifikasi adalah sebesar 78,86\%. Karakter "alif", " $b a$ ", " $t a "$ mampu diklasifikasi secara sempurna, sedangkan karakter " $t s a$ " hanya mampu diklasifikasi "90\%". Hal ini disebabkan kemiripan karakter "tsa" dan "nya" (ت ن). Karakter yang paling rendah mampu diklasifikasi adalah karakter "dhad" (ض) dan 
"hamzah" (є). Kedua karakter tersebut hanya mampu diklasifikasi sebesar 45\%. Hasil lengkap klasifikasi dapat dilihat pada tabel 2 .

Tabel 2. Akurasi klasifikasi per karakter

\begin{tabular}{|c|c|c|c|c|c|}
\hline \multicolumn{2}{|c|}{ Karakter } & \multicolumn{2}{|c|}{ Keberhasilan } & \multicolumn{2}{|c|}{ Persentase } \\
\hline Latin & Jawi & Berhasil & Gagal & $\begin{array}{c}\text { Berhasil } \\
(\%)\end{array}$ & $\begin{array}{c}\text { Gagal } \\
(\%)\end{array}$ \\
\hline alif & 1 & 20 & 0 & 100 & 0 \\
\hline ba & ب ب & 20 & 0 & 100 & 0 \\
\hline ta & $ت$ & 20 & 0 & 100 & 0 \\
\hline tsa & $\dot{ث}$ & 18 & 2 & 90 & 10 \\
\hline jim & ج & 19 & 1 & 95 & 5 \\
\hline hha & $\tau$ & 14 & 6 & 70 & 30 \\
\hline kha & $\dot{\tau}$ & 14 & 6 & 70 & 30 \\
\hline dal & د & 15 & 5 & 75 & 25 \\
\hline dzal & $\dot{~}$ & 17 & 3 & 85 & 15 \\
\hline $\mathrm{ra}$ & J & 15 & 5 & 75 & 25 \\
\hline zai & j & 20 & 0 & 100 & 0 \\
\hline $\sin$ & س س س & 20 & 0 & 100 & 0 \\
\hline syin & ش ش & 17 & 3 & 85 & 15 \\
\hline shad & ص ص & 17 & 3 & 85 & 15 \\
\hline dhad & ض ض & 9 & 11 & 45 & 55 \\
\hline tho & b & 10 & 10 & 50 & 50 \\
\hline zho & ظ & 16 & 4 & 80 & 20 \\
\hline ain & $\varepsilon$ & 13 & 7 & 65 & 35 \\
\hline ghain & $\dot{\varepsilon}$ & 16 & 4 & 80 & 20 \\
\hline $\mathrm{fa}$ & ف & 16 & 4 & 80 & 20 \\
\hline qaf & ق & 20 & 0 & 100 & 0 \\
\hline kaf & $s$ & 19 & 1 & 95 & 5 \\
\hline lam & J & 19 & 1 & 95 & 5 \\
\hline $\operatorname{mim}$ & s & 13 & 7 & 65 & 35 \\
\hline nun & ن & 17 & 3 & 85 & 15 \\
\hline wau & g & 13 & 7 & 65 & 35 \\
\hline ha & 。 & 11 & 9 & 55 & 45 \\
\hline hamzah & 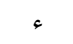 & 9 & 11 & 45 & 55 \\
\hline ya & ي & 20 & 0 & 100 & 0 \\
\hline
\end{tabular}

\begin{tabular}{lccccc}
\hline nya & $\dot{u}$ & 17 & 3 & 85 & 15 \\
ca & $\Xi$ & 20 & 0 & 100 & 0 \\
nga & $\dot{\varepsilon}$ & 20 & 0 & 100 & 0 \\
pa & $\vdots$ & 11 & 9 & 55 & 45 \\
ga & $\vdots$ & 7 & 13 & 35 & 65 \\
va & $\dot{3}$ & 10 & 10 & 50 & 50 \\
\hline
\end{tabular}

\section{Kesimpulan}

Pengenalan karakter tulisan tangan Jawi pada penelitian ini menggunakan fitur sudut yang dihasilkan dari kurva bagian utama karakter. Penggunaan fitur sudut mampu di klasifikasi SVM kedalam karakter Jawi dengan rata-rata keberhasilan sebesar $78,86 \%$. Beberapa kegagalan klasifikasi terjadi karena sudut yang dibentuk oleh kurva memiliki kesamaan dengan karakter lain.

\section{REFERENSI}

[1] H. Modi and M. C., "A Review on Optical Character Recognition Techniques,” Int. J. Comput. Appl., vol. 160, no. 6, pp. 20-24, 2017.

[2] L. M. Lorigo and V. Govindaraju, "Offline Arabic Handwriting Recognition :," IEEE Trans. Pattern Anal. Mach. Intell., vol. 28, no. 5, pp. 712-724, 2006.

[3] M. F. Nasrudin, K. Omar, M. S. Zakaria, and L. C. Yeun, "Handwritten Cursive Jawi Character Recognition: A Survey," pp. 247-256, 2008.

[4] . S., F. Arnia, and R. Muharar, "Pengenalan Aksara Jawi Tulisan Tangan Menggunakan Freemen Chain Code (FCC), Support Vector Machine (SVM) dan Aturan Pengambilan Keputusan,” J. Nas. Tek. Elektro, vol. 5, no. 1, p. 45, 2016.

[5] R. Redika, F. Teknologi, K. Omar, F. Teknologi, and F. Teknologi, "Handwritten Jawi Words Recognition Using Hidden Markov Models," pp. 4-8, 2008.

[6] M. F. Nasrudin, M. Petrou, and L. Kotoulas, "Jawi Character Recognition using the Trace Transform," 2010.

[7] A. Heryanto, F. Teknologi, S. Maklumat, F. Teknologi, K. Omar, and F. Teknologi, "Offline Jawi Handwritten Recognizer Using Hybrid Artificial Neural Networks and Dynamic Programming," 2008.

[8] T. R. Singh, S. Roy, O. I. Singh, T. Sinam, and K. M. Singh, "A New Local Adaptive Thresholding Technique in Binarization," vol. 8, no. 6, pp. 271-277, 2012.

[9] N. K. Garg, "Binarization Techniques used for Grey Scale Images," vol. 71 , no. 1 , pp. 8-11, 2013 .

[10] N. Otsu, "A Threshold Selection Method from Gray-Level Histograms,” IEEE Trans. Syst. Man. Cybern., 2008.

[11] T. Y. Zhang and C. Y. Suen, "A fast parallel algorithm for thinning digital patterns," Commun. ACM, 1984.

[12] L. Lam and S. W. Lee, "Thinning methodologies - a comprehensive survey,” IEEE Trans. Pattern Anal. Mach. Intell., 1992. 